\title{
Usporedba tradicijskog kultivara heljde sjeverozapadne Hrvatske sa stranim sortama
}

\section{Sažetak}

Običnaheljda(Fagopyrumesculentum Moench) posljednjihgodinaprivuklajevelikupozornostzbogvisoke prehrambene vrijednosti i ljekovitih svojstava. Ova kultura ima dugu povijest uzgoja u sjeverozapadnoj Hrvatskoj, a posebno je interesantna u sustavu ekološkog uzgoja. Posljednjih godina raste interes za proizvodnjom i konzumiranjem heljde, no problem predstavlja nedostatak odgovarajućeg sjemenskog materijala. Naime na sortnoj listi Republike Hrvatske nema niti jedne upisane sorte heljde, te se sadašnja proizvodnja temelji uglavnom na sjemenu tradicijskih kultivara (lokalnih populacija) te na uvozu stranih (uglavnom slovenskih) sorata od strane vlasnika OPG-ova. Cilj ovog rada je informirati stručnu javnost o utjecaju načina proizvodnje i roka sjetve na morfološka i agronomska svojstva tradicijskog kultivara heljde Varaždinska. Na osnovu rezultata ovog istraživanja nije utvrđena značajna razlika tradicijskog kultivara u odnosu na strane sorte ni u jednom od mjerenih morfoloških (visina biljke, broj grana po biljci i broj cvatova po biljci) i agronomskih (masa zrna po biljci i masa 1000 zrna) svojstava. Način proizvodnje (konvencionalni, ekološki) također nije značajno utjecao na prosječne vrijednosti mjerenih morfoloških $i$ agronomskih svojstava, iako je utvrđena veća vrijednost morfoloških svojstava u ekološkoj proizvodnji.

Ključne riječi: heljda, tradicijski kultivar, morfološka svojstva, agronomska svojstva, ekološka proizvodnja, konvencionalna proizvodnja

\section{Uvod}

Heljda (Fagopyrum esculentum Moench) je vrlo stara krušarica porijeklom iz Azije. U Hrvatskoj se počela proizvoditi još u 15. stoljeću. Heljda je donedavno bila gotovo zaboravljena kultura, no jačanjem svijesti o zdravoj prehrani u posljednje vrijeme, heljda ponovo dobiva na značaju. Obzirom da ne sadrži gluten (kao prave žitarice), jedna je od osnovnih namirnica u bezglutenskoj prehrani. Može se uzgajati uz vrlo niska ulaganja, kao glavna ili dopunska (postrna) kultura nakon uzgoja ozimih žitarica, a kao takva posebno je interesantna u sustavu ekološkog uzgoja jer može osigurati značajan dodatni prihod na obiteljskim poljoprivrednim gospodarstvima. Odlično prorahljuje tlo te zahvaljujući gustom sklopu guši korove. U dosadašnjim istraživanjima (Kalinova i Vrchotova, 2011.; Popović i sur., 2013.) nije utvrđena značajna razlika u masi zrna po biljci, kao ni u masi 1000 zrna između ekološke i konvencionalne proizvodnje. Ekološki uzgoj je vrlo perspektivan jer konzumenti heljde, skloni alternativnim načinima prehrane, preferiraju organski uzgojenu hranu. Procjene su da se $90 \%$ heljde koja dolazi do krajnjeg potrošača u Hrvatskoj uvozi iz Ukrajine, Rusije i Kine. U Republici Hrvatskoj heljda se tradicijski proizvodi u sjeverozapadnom dijelu i to u Hrvatskom zagorju, Podravini i Međimurju. Proizvodnja donedavno nije bila poticana državnim sredstvima pa je posljedično tome u poljoprivrednoj proizvodnji postala nepravedno zanemarena kultura. Danas, kada se povećava interes za konzumiranjem i proizvodnjom heljde, problem je nedostatak odgovarajućeg sjemenskog materijala. Raniji pad interesa za proizvodnju heljde najvjerojatnije je bio razlog povlačenja sorata sa sortne liste, pa na sortnoj listi Republike Hrvatske danas nema niti jedne upisane sorte heljde. Sadašnja se proizvodnja zato temelji uglavnom na sjemenu tra-

doc. dr.sc. Ivanka Habuš Jerčić, dr.sc. MajaŽulj Mihaljević, prof. dr. sc. Jerko Gunjača, doc. dr. sc. Anita Bošnjak Mihovilović, prof. dr. sc. Snježana Kereša, prof. dr. sc. Marijana Barić, Edita Baričević, Sveučilište u Zagrebu Agronomski fakultet, Svetošimunska cesta 25, 10000 Zagreb, Hrvatska Mara Bogović, mag. ing.agr., Ministarstvo poljoprivrede, Uprava za stručnu podršku razvoju poljoprivrede i ribarstva, Anina 11, 42000Varaždin, Hrvatska Autor za korespondenciju: ihabus@agr.hr 
dicijskih kultivara (lokalnih populacija) te na uvozu stranih (uglavnom slovenskih) sorata od strane vlasnika OPG-ova.

Cilj ovog rada je informirati stručnu javnost o utjecaju načina proizvodnje i roka sjetve na morfološka i agronomska svojstva tradicijskog kultivara heljde Varaždinska.

\section{Materijali i metode}

$U$ istraživanje je bila uključena varaždinska populacija heljde te dvije sorte iz različitih oplemenjivačkih programa: Darja (slovenska sorta; Semenarna Ljubljana) i Novosadska (srpska sorta, Institut za ratarstvo i povrtlarstvo Novi Sad).

Pokus je bio postavljen tijekom vegetacijske godine 2017. na tri odvojene lokacije u dva roka sjetve te dva načina proizvodnje, ekološka ili konvencionalna proizvodnja (Tablica 1.):

Tablica 1. Datumi sjetve i žetve glavnog i postrnog usjeva na tri lokacija/

Table 1. Sowing and harvesting dates of main and stubble crops on three locations

\begin{tabular}{lccccc}
\hline & \multicolumn{2}{c}{$\begin{array}{c}\text { Glavni usjev/ } \\
\text { Main crop }\end{array}$} & \multicolumn{2}{c}{$\begin{array}{c}\text { Postrni usjev/ } \\
\text { Stubble crop }\end{array}$} \\
\hline Lokacije/Locations & $\begin{array}{c}\text { Način proizvodnje/ } \\
\text { Cropping system }\end{array}$ & $\begin{array}{l}\text { Sjetva/ } \\
\text { Sowing }\end{array}$ & $\begin{array}{c}\text { Žetva/ } \\
\text { Harvest }\end{array}$ & $\begin{array}{l}\text { Sjetva/ } \\
\text { Sowing }\end{array}$ & $\begin{array}{c}\text { Žetva/ } \\
\text { Harvest }\end{array}$ \\
\hline Sveta Marija (SM) & $\begin{array}{c}\text { Ekološka/ } \\
\text { Organic }\end{array}$ & 31.5. & 19.10. & 5.7. & 2.11. \\
\hline Varaždin (V) & $\begin{array}{c}\text { Konvencionalna/ } \\
\text { Conventional }\end{array}$ & 2.6. & 12.10. & 6.7. & 5.11. \\
\hline Maksimir(M) & $\begin{array}{c}\text { Konvencionalna/ } \\
\text { Conventional }\end{array}$ & $/$ & $/$ & 20.7. & 15.11. \\
\hline
\end{tabular}

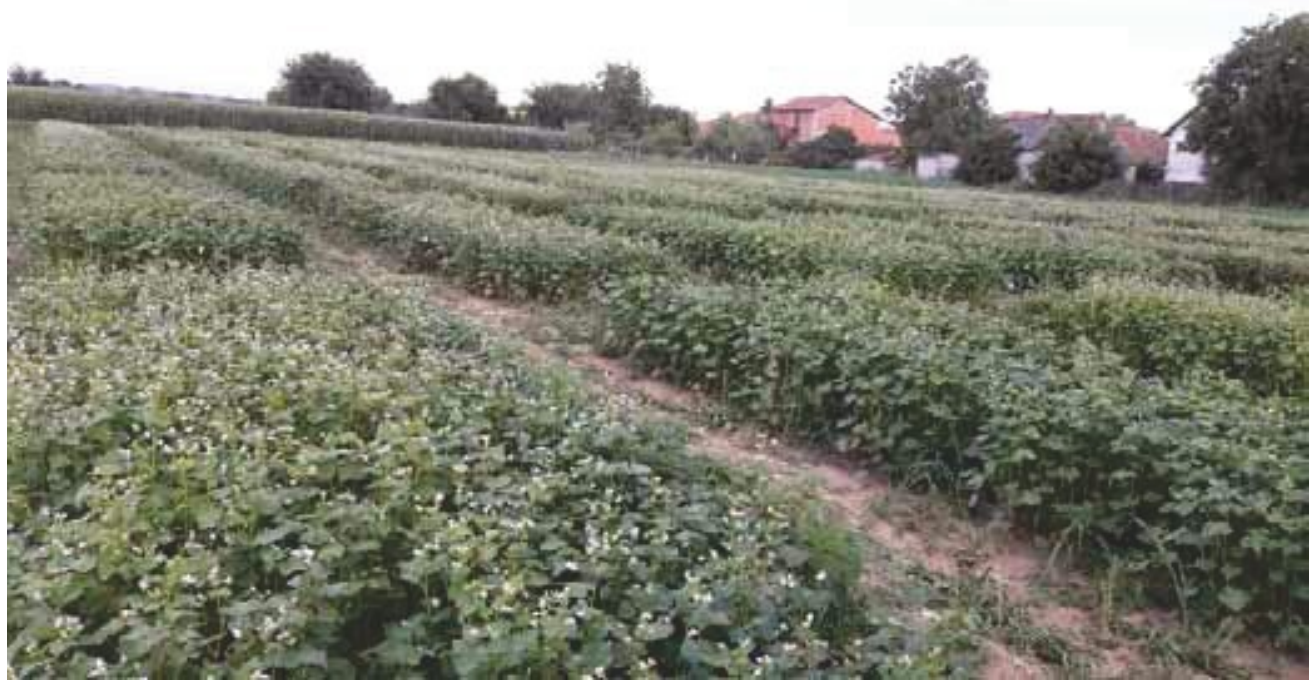

Slika 1. Prikaz pokusa na lokaciji Varaždin (glavni usjev)/

Picture 1. Field trail in Varaždin (main crop) 
Pokus je zasijan po shemi split plot desinga u tri repeticije (slika 1.), a gustoća sjetve je bila $80 \mathrm{~kg} / \mathrm{ha}$. Korišteni su uobičajeni agrotehnički postupci u proizvodnji heljde. Obrada tla uključivala je duboko oranje, tanjuranje i predsjetvenu pripremu rotodrljačom. Kod postrnog usjeva, prije zaoravanja žetvenih ostataka u konvencionalnoj proizvodnji dodano je $100 \mathrm{~kg} / \mathrm{ha}$ uree, a u ekološkoj 100 kg/ha Bioilsa Fertil (12,5\% N) organskog dušičnog gnojiva.

Tijekom vegetacije provedena je samo mehanička obrada protiv korova. Žetva je provedena u punoj zrelosti u drugoj polovici listopada za usjev sijan u glavnom roku sjetve te početkom studenog za usjev sijan u postrnom roku.

Prije žetve ručno su uzimani uzorci od po 20 biljaka po parcelici na kojima su mjerena morfološka i agronomska svojstva (Tablica 2.). Statistička analiza uključivala je analizu varijance te su na osnovu izračunatih prosječnih vrijednosti izrađene tablice za morfološka i agronomska svojstva.

Tablica 2. Morfološka i agronomska svojstva/

Table 2. Morphological and agronomic traits

\begin{tabular}{cc}
\hline $\begin{array}{c}\text { Morfološka svojstva/ } \\
\text { Morphological traits }\end{array}$ & $\begin{array}{c}\text { Agronomska svojstva/ } \\
\text { Agronomic traits }\end{array}$ \\
\hline $\begin{array}{c}\text { Visina biljke }(\mathrm{cm}) / \\
\text { Plant height }\end{array}$ & Masa zrna po biljci (g)/ \\
\hline Broj grana po biljci/ & Grain weight per plant $(\mathrm{g})$ \\
\hline Number of branches per plant & \\
\hline Broj cvatova po biljci/ & Masa 1000 zrna $(\mathrm{g}) /$ \\
Number of inflorescences per plant & 1000 grain weight $(\mathrm{g})$ \\
\hline
\end{tabular}

Klimatski uvjeti na sve tri lokacije nisu se značajno razlikovali. Ljetni mjeseci bili su topli i suhi. Prosječna dnevna temperatura na sve tri lokacije bila je oko $22{ }^{\circ} \mathrm{C}$, a mjesečno nije palo više od $70 \mathrm{~mm}$ kiše. Mjesec kolovoz bio je najsušniji s manje od $50 \mathrm{~mm}$ oborina te je izmjerena maksimalna temperatura iznosila $37,7^{\circ} \mathrm{C}$. U rujnu je količina oborina iznosila više od $200 \mathrm{~mm}$ što je bio maksimum u periodu vegetacije heljde, a prosječna dnevna temperatura u razdoblju dozrijevanja heljde pala je s $24^{\circ} \mathrm{C}$ na $7{ }^{\circ} \mathrm{C}$.

\section{Rezultati i rasprava}

\section{Morfološka svojstva}

Od morfoloških svojstava praćeni su visina biljke, broj grana po biljci i broj cvatova po biljci, dok su od agronomskih svojstava praćeni masa zrna po biljci i masa 1000 zrna.

Na morfološka svojstva značajno je utjecao rok sjetve (Tablica 3). U postrnom roku sjetve izmjerene su značajno niže biljke, manji broj grana i cvatova na svim lokacijama kod svih genotipova. Naime, heljda je vrlo osjetljiva na fotoperiodizam. Na visinu biljke značajno utječe duljina dana u prvih 20 - 30 dana vegetativnog rasta i razvoja cvijeta. Dugi fotoperiodi (duljina danjeg svjetla 14 - $18 \mathrm{~h}$ ) pogoduju izduživanju stabljike, dok kratki fotoperiodi (duljina dnevnog svjetla 9 - 10 h) inhibiraju izduživanje stabljike (Woo i sur., 2010). Michiyama i sur. (2003.) utvrdili su da biljke izložene dugom danu prije početka cvatnje produže vegetativnu fazu $\mathrm{i}$ izduže prvi cvjetni nodij, što uvjetuje višu stabljiku. Arduini i sur. (2016.) također su utvrdili da razlika u temperaturi i duljini dana, uvjetovana različitim rokom sjetve, utječe na izduživanje internodija glavne stabljike i rast bočnih grana. Duži dani i više temperature rezultiraju značajnijim povećanjem u visine biljke i broja cvatova po biljci.

Prema prosječnim vrijednostima visine stabljike kod svih populacija i sorata utvrđena je 
viša stabljika na lokaciji Sveta Marija u ekološkom sustavu proizvodnje. Tradicijski kultivar Varaždinska nije se značajno razlikovao u visini stabljike u odnosu na strane sorte, a visina kod glavnog usjeva mu je iznosila ovisno o lokaciji i uvjetima uzgoja od 136,47 do 140,37 cm.

Međutim, u postrnom roku sjetve značajnije razlike u visini stabljike na lokaciji Sveta Marija (ekološka proizvodnja) i Maksimir (konvencionalna proizvodnja) nije bilo, dok je značajna razlika utvrđena za lokaciju Varaždin. Na lokaciji Varaždin izmjerena je najmanja visina biljke kod svih genotipova u oba roka sjetve. U postrnom roku sjetve na sve tri lokacije utvrđena je najveća visina kod tradicijskog kultivara Varaždinska, a kretala se od 70,29 do 89,80 cm.

Arudini i suradnici (2016.) utvrdili su da visina biljke značajno utječe na formiranje broja grana i broja cvatova po biljci. Stoga ne iznenađuje činjenica da je najveći broj grana po biljci i broj cvatova po biljci kod glavnog usjeva utvrđen na lokaciji Sveta Marija u ekološkoj proizvodnji gdje je izmjerena i najveća visina biljaka. Sorta Novosadska imala je najveći broj grana i cvatova $(5,67$, odnosno 38,8$)$, a za nju je utvrđena i najveća visina biljke. Broj grana po biljci kod tradicijskog kultivara Varaždinska bio je nešto manji u odnosu na strane sorte i kretao se od 0,62 do 3,59. lako je broj grana kultivara Varaždinska bio manji, značajne razlike u broju grana, na istoj lokaciji i u istim uvjetima uzgoja, među genotipovima nije bilo.

Kod postrnog usjeva najveći broj grana i cvatova po biljci utvrđen je u konvencionalnoj proizvodnji na lokaciji Maksimir, a genotip kod kojeg je utvrđen najveći broj grana je sorta Darja $(2,07)$. Tradicijski kultivar Varaždinska imao je najmanji broj grana po biljci na svim lokacijama u oba roka sjetve $(0,62$ do 3,29$)$.

Tablica 3. Prosječne vrijednosti morfoloških svojstava/

Table 3. Average values of morphological traits

\begin{tabular}{|c|c|c|c|c|c|c|}
\hline \multirow[t]{2}{*}{$\begin{array}{l}\text { Svojstvo/ } \\
\text { Trait }\end{array}$} & \multirow[t]{2}{*}{$\begin{array}{l}\text { Genotip/ } \\
\text { Genotype }\end{array}$} & \multicolumn{2}{|c|}{$\begin{array}{c}\text { Varaždin } \\
\text { konvencionalna/ } \\
\text { Varaždin conventional }\end{array}$} & \multicolumn{2}{|c|}{$\begin{array}{l}\text { Sveta Marija } \\
\text { ekološka/ } \\
\text { Sveta Marija } \\
\text { organic }\end{array}$} & \multirow{2}{*}{$\begin{array}{c}\text { Maksimir } \\
\text { konvencionalna } \\
\text { Maksimir } \\
\text { conventional }\end{array}$} \\
\hline & & $\begin{array}{c}\text { Glavni/ } \\
\text { Main }\end{array}$ & $\begin{array}{l}\text { Postrni/ } \\
\text { Stubble }\end{array}$ & $\begin{array}{c}\text { Glavni/ } \\
\text { Main }\end{array}$ & $\begin{array}{l}\text { Postrni/ } \\
\text { Stubble }\end{array}$ & \\
\hline \multirow{3}{*}{$\begin{array}{l}\text { Visina biljke }(\mathrm{cm}) / \\
\text { Plant height }(\mathrm{cm})\end{array}$} & Varaždinska & 136,47 & 70,29 & 140.37 & 89.80 & 88.86 \\
\hline & Darja & 133,33 & 60,69 & 154.8 & 89.11 & 78.28 \\
\hline & Novosadska & 143,25 & 66,11 & 162.07 & 87.06 & 74.70 \\
\hline \multirow{3}{*}{$\begin{array}{l}\text { Broj grana po biljci/ } \\
\text { Number of branches } \\
\text { per plant }\end{array}$} & Varaždinska & 1,64 & 0,62 & 3.59 & 1.12 & 1.41 \\
\hline & Darja & 1,66 & 0,77 & 4.93 & 1.59 & 2.07 \\
\hline & Novosadska & 1,99 & 0,80 & 5.67 & 1.49 & 1.51 \\
\hline \multirow{3}{*}{$\begin{array}{l}\text { Broj cvatova po } \\
\text { biljci/ } \\
\text { Number of } \\
\text { inflorescences per } \\
\text { plant }\end{array}$} & Varaždinska & 15,57 & 7,42 & 25.70 & 14.07 & 16.00 \\
\hline & Darja & 11,38 & 8,02 & 29.47 & 14.26 & 20.07 \\
\hline & Novosadska & 17,69 & 7,58 & 38.8 & 13.29 & 17.12 \\
\hline
\end{tabular}




\section{Agronomska svojstva}

Od agronomskih svojstava praćeni su masa 1000 zrna i masa zrna po biljci (Tablica 4). Na agronomska svojstva nije značajno utjecala lokacija (način proizvodnje).

Masa 1000 zrna nije se značajno razlikovala u odnosu na lokaciju i način proizvodnje, međutim veća masa je utvrđena u postrnom roku sjetve kod svih genotipova. Najveća masa 1000 zrna utvrđena je kod sorte Novosadska, a kretala se od 22,44 g do 25,56 g. lako se masa 1000 zrna tradicijskog kultivara Varaždinska nije značajno razlikovala od drugih sorata, kod njega je utvrđena najmanja masa 1000 zrna, osim na lokaciji Sveta Marija (ekološka proizvodnja) kod glavnog usjeva gdje je sorta Darja imala najmanju masu 1000 zrna.

Rok sjetve značajno je utjecao i na masu zrna po biljci. Usprkos tome što je utvrđen daleko veći broj cvatova kod biljaka sijanih u ranijem roku sjetve (zbog duljine dnevnog svijetla), kod svih genotipova utvrđena je veća masa zrna po biljci, kao i masa 1000 zrna kod postrnog roka sjetve. Taylor i Obendorf (2001), također su utvrdili niži prinos kod biljaka ranijeg roka sjetve. Oni niži prinos pripisuju nepovoljnim vanjskim uvjetima (visokoj temperaturi i suši), koji značajno utječu na formiranje zrna te neuspjehu u oplodnji povezanim s unutarnjim čimbenicima, kao što su kompeticija među biljnim organima za dostupnim hranjivima. U ovom istraživanju su upravo nepovoljni vanjski uvjeti (suša i visoka temperatura) bili ograničavajući faktor koji je utjecao na malu masu zrna po biljci i malu masu 1000 zrna kod glavnog usjeva.

U masi zrna po biljci genotipovi su se razlikovali s obzirom na rok sjetve i lokaciju (način proizvodnje). U postrnom roku sjetve kod konvencionalne proizvodnje na lokacijama Varaždin i Maksimir, tradicijski kultivar Varaždinska imao je najveću masu zrna po biljci (3,97, odnosno 5,39 g).

Tablica 4. Prosječne vrijednosti agronomskih svojstava/

Table 4. Average value of agronomic traits

\begin{tabular}{|c|c|c|c|c|c|c|}
\hline \multirow[t]{2}{*}{$\begin{array}{c}\text { Svojstvo/ } \\
\text { Trait }\end{array}$} & \multirow[t]{2}{*}{$\begin{array}{l}\text { Genotip/ } \\
\text { Genotype }\end{array}$} & \multicolumn{2}{|c|}{$\begin{array}{c}\text { Varaždin } \\
\text { konvencionalna/ } \\
\text { Varaždin } \\
\text { conventional }\end{array}$} & \multicolumn{2}{|c|}{$\begin{array}{l}\text { Sveta Marija } \\
\text { ekološka/ } \\
\text { Sveta Marija } \\
\text { organic }\end{array}$} & \multirow{2}{*}{$\begin{array}{c}\text { Maksimir } \\
\text { konvencionalna/ } \\
\begin{array}{c}\text { Maksimir } \\
\text { convetional }\end{array} \\
\begin{array}{c}\text { Postrni/ } \\
\text { Stubble }\end{array}\end{array}$} \\
\hline & & $\begin{array}{c}\text { Glavni/ } \\
\text { Main }\end{array}$ & $\begin{array}{l}\text { Postrni/ } \\
\text { Stubble }\end{array}$ & $\begin{array}{c}\text { Glavni/ } \\
\text { Main }\end{array}$ & $\begin{array}{l}\text { Postrni/ } \\
\text { Stubble }\end{array}$ & \\
\hline \multirow{3}{*}{$\begin{array}{l}\text { Masa } 1000 \\
\text { zrna (g)/ } \\
1000 \text { grain } \\
\text { weight }(\mathrm{g})\end{array}$} & Varaždinska & 20.89 & 22.00 & 22.00 & 22.29 & 22.67 \\
\hline & Darja & 21.56 & 24.00 & 21.33 & 22.57 & 23.56 \\
\hline & Novosadska & 22.44 & 25.56 & 23.33 & 25.20 & 25.56 \\
\hline \multirow{3}{*}{$\begin{array}{l}\text { Masa zrna } \\
\text { po bilici (g)/ } \\
\text { Grain weight } \\
\text { per plant (g) }\end{array}$} & Varaždinska & 2.08 & 3.97 & 1.7 & 2.05 & 5.39 \\
\hline & Darja & 1.58 & 3.64 & 1.43 & 1.69 & 4.64 \\
\hline & Novosadska & 2.16 & 3.69 & 2.2 & 2.79 & 4.8 \\
\hline
\end{tabular}

\section{Zaključak}

lako je kultivar Varaždinska heterogena populacija heljde, na osnovu rezultata ovog istraživanja nije utvrđena značajna razlika tradicijskog kultivara u odnosu na strane sorte ni u jednom od mjerenih morfoloških (visina biljke, broj grana po biljci i broj cvatova po biljci) i agronomskih (masa zrna po biljci i masa 1000 zrna) svojstava. Način proizvodnje (konvencionalni, ekološki) također nije značajno utjecao na prosječne vrijednosti mjerenih morfoloških i agro- 
nomskih svojstava, iako je utvrđena veća vrijednost morfoloških svojstava u ekološkoj proizvodnji kod glavnog usjeva. Rok sjetve imao je značajan utjecaj na mjerena svojstva kod svih genotipova, pa tako i kod tradicijskog kultivara Varaždinska. Rok sjetve značajno je utjecao na prosječne vrijednosti morfoloških svojstava, koje su bile niže kod postrnog roka. Usprkos nižim vrijednostima morfoloških svojstava u postrnom roku, prosječna masa zrna po biljci kao i masa 1000 zrna bile su veće kod postrnog roka sjetve. Imajući u vidu sva morfološka i agronomska svojstva tradicijskog kultivara te njegovu adaptiranost na agroekološke uvjete sjeverozapadne Hrvatske možemo očekivati povećanje površina zasijanih ovim kultivarom.

\title{
Napomena/Zahvala
}

Rezultati prezentirani u radu nastali su kao rezultat istraživačkog projekta 2016-14-8,,Revitalizacija lokalnih sorti heljde za uzgoj na obiteljskim poljoprivrednim gospodarstvima sjeverozapadne Hrvatske“.

\section{Literatura}

Arduini, I., Masoni, A., Mariotti, M. (2016) A growth scale for the phasic development of common buckwheat. Acta Agriculture Scandinavica: Section B-Soil \&amp; Plant Science. 66(3), 215-228. DOI: 10.1080/09064710.2015.1087587

Kalinova, J., Vrchotova, N. (2011) The influence of organic and conventional crop

management, variety and year on the yeal and flavonoid level in common buckwheat

groats. Food Chemistry 127(2), 602-608. DOI: 10.1016/j.foodchem.2011.01.050

Michiyama, H., Arikuni, M., Hirano, T., Hayashi, H. (2003) Influence of day length before and after the start of anthesis on the growth, flowering and seed-setting in common

buckwheat (Fagopyrum esculentum Moench). Plant Production Science. 6, 235-242.

Popović, V., Sikora, V., Glamočlija, Đ., Ikanović, J., Filipović, V., Tabaković, M., Simić, D. (2013) Influence of agro-ecological conditions and foliar fertilization on yeald and yeald components of buckwheat in conventional and organic cropping system. Biotechnology in Animal Husbandry. 29(3), 537-546. DOI: 10.2298/BAH1303537P

Taylor, D. P., Obendorf, R. L. (2001) Quantitative assessment of some factors limiting seed set in buckwheat. Crop Science. 41, 1792-1799. DOI: 10.2135/cropsci2001.1792

Woo, S., Kamal, A., Tatsuro, S., Campbell, C., Adachi, T., Yun, Y., Chung, K., Choi, J. (2010) Buckwheat (Fagopyrum esculentum Moench.): Concepts, Prospects and Potential. The European Journal of Plant Science and Biotechnology. 4(1), 1-16.

Prispjelo/Received: 1.7.2020.

Prihvaćeno/Accepted: 3.9.2020.

Professionalpaper

\section{Comparison of the traditional buckwheat cultivar of northwestern Croatia with foreign varieties}

\begin{abstract}
Due to its high nutritional value and medicinal properties buckwheat (Fagopyrum esculentum Moench) has attracted increasing attention in recent years. This crop has a long history of cultivation in northwestern Croatia. There is special interest in growing buckwheat in organic cropping system. In recent years, interest on the production and consumption of buckwheat is growing, but the problem is the lack of appropriate seed material. Not a single variety of buckwheat is registered on the variety list of the Republic of Croatia, and the current production is based mainly on seeds of traditional cultivars (local populations) and on the import of foreign (mostly Slovenian) varieties by family farm owners. The aim of this paper is to inform the professional public about the impact of cropping systems and sowing dates on the morphological and agronomic traits of the traditional buckwheat cultivar Varaždinska. Based on the results of this research, no significant difference was found between the traditional cultivar in relation to foreign varieties in any of the measured morphological (plant height, number of branches per plant and number of inflorescences per plant) and agronomic (grain weight per plant and 1000 grain weight) traits. The cropping systems (conventional, organic) also did not significantly affect the average values of the measured morphological and agronomic traits, although a higher value of morphological traits in organic cropping system was found. Keywords: buckwheat, traditional cultivar, morphological traits, agronomic traits, organic cropping system, conventional cropping system
\end{abstract}

